\title{
PEMANFAATAN LIMBAH MARMER SEBAGAI BAHAN CAMPURAN UNTUK PEMBUATAN PAVING BLOCK
}

Fadlillah Fauziah, Demes Nurmayanti, Fitri Rokhmalia

\begin{abstract}
Until now the utilization of marble waste has not been maximized. Perminggu can produce waste of \pm 1 to 10 tons. Paving blocks generally use a mixture of sand and cement with a ratio of $1: 5$. The purpose of this study is to determine the effect of differences in compressive strength and water absorption with different compositions and day testing with reference to standards (SNI 03-0691-1996).

Here try to use waste used for Paving blocks with 4 variations mixed 1 Pc: 5 Ps, 1 Pc: 5 Lm, 1 Pc: 3 Lm: 2 Ps, 1 Pc: 2 Lm: 3 Ps with test compressive and water absorption days to $-7,14,21$ and 28 days. This research is an experimental study using the Pottest Only Control Group Design design and the data were analyzed by One Way Anova test.

The results showed that the compressive strength test on the control and 4 variations at the highest 28th day was $2.10 \mathrm{MPa}$ and the variation of $\mathrm{B}$ code was 0.86 , C code 1.47 and D code $2.09(\mathrm{MPa})$. Water absorption test results meet a maximum standard of $10 \%$ absorption. The results of One Way Anova test are $0.001<0.05$, which means that $\mathrm{Ho}$ is rejected, there is a difference in compressive strength and Paving block water absorption with the three group variations.

Conclusion The compressive strength of Paving block control and 4 variations were highest at 28 days $2.10 \mathrm{MPa}$ and composition D 2.09 MPa but still below standard. Paving block water absorption test meets the standard. It is recommended that the researcher then add a mixture of 2 Pc: $3 \mathrm{Lm}$ : 5 Ps and the addition of 35 days.
\end{abstract}

Keywords: Marble Waste, Press Strength, Water Absorption, Paving Block

\section{Pendahuluan}

Di wilayah Kabupaten

Tulungagung terdapat beberapa industri diantaranya yang paling banyak yaitu industri marmer yang diolah dan dimanfaatkan oleh masyarakat sekitar untuk dijadikan interior bangunan, tetapi karena jumlahnya yang berlimpah maka limbah yang dihasilkan juga semakin meningkat makanya perlu adanya cara untuk mengatasi dan di kembangkan teknologi pemanfaatan limbah untuk dimanfaatkan sebagai bahan bangunan ramah lingkungan didapatkan dari hasil wawancara, limbah yang dihasilkan mencapai \pm 1 sampai 10 ton per minggu. 
Berdasarkan nilai ekonominya limbah dibedakan menjadi limbah yang mempunyai nilai ekonomis dan limbah yang tidak memiliki nilai ekonomis. Limbah yang memiliki nilai ekonomis yaitu limbah dimana dengan melalui suatu proses lanjut akan memberikan suatu nilai tambah. Limbah non ekonomis adalah suatu limbah yang walaupun telah dilakukan proses lanjut dengan cara apapun tidak akan memberikan nilai tambah kecuali sekedar untuk mempermudah sistem pembuangan. Limbah jenis ini sering menimbulkan masalah pencemaran dan kerusakan lingkungan (Kristanto, 2002).

Limbah yang dihasilkan pada industri umumnya berupa limbah padat dan limbah cair. Limbah padat yang dihasilkan berupa sisa produk yang sudah tidak digunakan kembali salah satunya yaitu limbah marmer. Limbah cair pada industri yang dihasilkan umumnya merupakan limbah organik yang dapat membusuk atau terdegradasi oleh mikroorganisme. Industri marmer menghasilkan limbah marmer yang mengandung bahan kimia di antaranya Silikon dioksida $\left(\mathrm{SiO}_{2}\right)$,
Kalsium Oksida (CaO), Magnesium Oksida (MgO) dan memungkinkan memiliki peranan sebagai penguat dalam bahan campuran bangunan.

Utami (2010) Pada penelitian komposisi campuran mengenai limbah marmer untuk pembuatan paving stone di antaranya adalah perbandingan 1PC : 5PS dengan viariasi komposisi campuran $1 \mathrm{Pc}: 5$ Ps : 0 Lm, 0,8 Pc : 0,2 Lm : 5 Ps, 0,6 Pc : 0,4 Lm : 5 Pc, 0,4 Pc : 0,6 Lm : 5 Ps, 0,2 Pc : 0,8 Lm : 5 Lm. Penelitian yang lain yaitu pemanfaatan limbah marmer dan serbuk zeolit sebagai material pada bata ringan CLC (Celullar Lightweight Concrete) dengan komposisi campuran 0,8 Pc : 0,2 Zlt : 0,3 Ps : 1,2 Psl dalam campuran bahan material dan mampu untuk dijadikan bahan pengganti pasir pada pembuatan bata ringan CLC (Aditya, 2017).

Keunggulan dari limbah marmer itu sendiri mampu menaikkan kekuatan beton pada penggunaan limbah marmer 5\% dari sebagai bahan pengerat karena komposisi yang ada pada limbah marmer terdapat senyawa $\mathrm{CaO}$ 
yang sama dengan kandungan senyawa yang ada pada semen yaitu 52,69\% (Utami, 2010).

Pemanfaatan limbah marmer ini diantaranya yaitu di gunakan untuk batako dengan hasil yang diperoleh menunjukkan pada nilai kuat tekan batako limbah marmer dengan komposisi campuran $1 \mathrm{Lm}$ : 5 Ps; 1,5 Lm : 5 Ps dan 2 Lm : 5 Ps diperoleh hasil nilai kuat tekan paling tinggi hari ke-28 sebesar 3,47 $\mathrm{kg} / \mathrm{cm}^{2}, 4,16 \mathrm{~kg} / \mathrm{cm}^{2}$ dan 6,05 $\mathrm{kg} / \mathrm{cm}^{2}$. kuat tekan sebesar 4,52 $\mathrm{kg} / \mathrm{cm}^{2}$ dan masih dibawah SNI 030691-1996 karena nilai SNI 030691-1996 nilai kuat tekannya untuk batako sebesar $40 \mathrm{~kg} / \mathrm{cm}^{2}$ (Dini, 2017).

Menurut Aditya (2016) pada penelitian pemanfaatan limbah marmer dan serbuk silika pada industri bata beton pejal dan berlubang hasil menunjukkan bahwa penggunaan serbuk silica dan pasir limbah marmer berpengaruh nyata dan menimbulkan perbedaan terhadap kuat tekan bata beton pejal dan berlubang. Penelitian yang lain dalam pemanfaatan limbah marmer dan serbuk zeolit sebagai material pada bata ringan, hasil penelitian menunjukkan bahwa penggunaan limbah marmer berupa pasir dan serbuk zeolit berpengaruh nyata dan menimbulkan perbedaan terhadap kuat tekan bata ringan dengan pemakaian pasir limbah marmer $\quad 20 \% \quad$ menimbulkan kenaikan kuat tekan sebesar 25,37\% dari komposisi acuan 1 Pc : 1,5 Ps. Pemanfaatan yang di gunakan dengan menggunakan limbah marmer di dapatkan hasil yang baik untuk di jadikan sebagai bahan campuran (Aditya, 2017).

Paving Block merupakan suatu komposisi bahan bangunan yang terbuat dari campuran semen Portland atau bahan perekat hidrolis lainnya, air dan agregat dengan atau tanpa bahan tambahan lainnya yang tidak mengurangi mutu beton tersebut (SNI 03-0691-1996). Paving block merupakan bahan bangunan yang dibuat dari campuran semen, pasir dan air, sehingga karasteristiknya hampir mendekati dengan karasteristik mortar. Mortar adalah bahan bangunan yang dibuat dari campuran antara pasir dan agregat 
halus dengan bahan pengikat dan air yang didalam keadaan keras yang mempunyai sifat seperti batuan (Artiyani, 2010).

\section{Metode Penelitian}

Jenis penelitian ini adalah penelitian eksperimen dengan menggunakan rancangan Posttest Only Control Group Design. Obyek yang digunakan adalah limbah marmer dari wilayah Campurdarat Kabupaten Tulungagung. Didalam penelitian ini dilakukan 4 perlakuan dengan jumlah replikasi yang di perlukan untuk 1 kontrol dan 3 perlakuan dengan setiap 1 perlakuan masing-masing membuat 20 buah, dengan tiap uji umur ke-7,
14, 21 dan 28 dengan komposisi 1 Pc : 5 Lm; 1 Pc : 3 Lm : 2 Ps; 1 Pc : $2 \mathrm{Lm}: 3$ Ps masing-masing membuat 5 buah. Jadi total membuat Paving block sebanyak 80 buah dengan pengujian pada hari ke-7, 14, 21 dan hari ke 28. Variabel bebas dalam penelitian ini adalah limbah marmer, pasir dan semen. Variabel terikatnya adalah kuat tekan dan serap air. Variabel penghubungnya adalah waktu pengeringan dan komposisi bahan.

\section{Hasil Penelitian}

1. Hasil uji kuat tekan Paving block dengan komposisi campuran Pasir dan Semen sebagai kontrol

Tabel 1. Hasil Uji Kuat Tekan Paving block Kontrol

\begin{tabular}{c|c}
\hline Hari ke- & $\begin{array}{c}\text { Kuat Tekan rata-rata Paving } \\
\text { Block (MPa) }\end{array}$ \\
\hline 7 & 1,82 \\
14 & 1,83 \\
21 & 1,99 \\
28 & 2,10 \\
\hline
\end{tabular}

Menurut SNI 03-0691-1996 standar kuat tekan bata beton mutu D yang digunakan untuk taman dan penguna lain yaitu rata-rata sebesar $10 \mathrm{MPa}$ dengan minimal 8,5 MPa. Berdasarkan standart tersebut ke 4 kelompok dengan pengujian hari ke 7,14 ,
21, dan 28 belum memenuhi syarat.

Pada penelitian lain yang dilakukan Dini (2017) yaitu penggunaan pemanfaatan limbah marmer untuk pembuatan batako dengan nilai uji kuat tekan sebesar 40,21 kg/ $\mathrm{cm}^{2}$. Pada 
penelitian yang lain dengan pengujian kuat tekan paving block kontrol dengan campuran 1 Semen : 6 Pasir menghasilkan nilai kuat tekan maksimum sebesar 193,44 kg/cm² (Anggia, 2016).

Penelitian lain Utami (2010) melakukan penelitian pemanfaatan limbah marmer untuk pembuatan paving stone dengan perbandingan 1 Pc : 5 Ps dengan hasil kuat tekan 156,23 $\mathrm{kg} / \mathrm{cm}^{2}$ dengan luas penampang $220,5 \mathrm{~cm}^{2}$. Komposisi lain yang menggunakan campuran 1 Pc : 4 Ps dengan kekuatan tekan sebesar $121 \mathrm{~kg} / \mathrm{cm}^{2}$ (Rommel, 2009).

2. Hasil uji kuat tekan Paving block dengan komposisi campuran Pasir dan Semen dan Limbah Marmer

Tabel 2. Hasil uji kuat tekan Paving block dengan komposisi campuran Pasir dan Semen dan Limbah Marmer

\begin{tabular}{|c|c|c|}
\hline \multirow[t]{2}{*}{ Hari ke- } & \multicolumn{2}{|c|}{$\begin{array}{c}\text { Kuat Tekan rata-rata Paving Block (MPa) } \\
\text { Komposisi Campuran }\end{array}$} \\
\hline & B & C \\
\hline 7 & 0,64 & 1,12 \\
\hline 14 & 0,69 & 1,33 \\
\hline 21 & 0,83 & 1,36 \\
\hline 28 & 0,86 & 1,47 \\
\hline \multicolumn{2}{|c|}{ Menunjukkan bahwa nilai } & gunakan sebagai bahan utama \\
\hline \multirow{3}{*}{\multicolumn{2}{|c|}{$\begin{array}{l}\text { kuat tekan Paving block dengan } \\
\text { menggunakan campuran limbah } \\
\text { marmer dengan kode B, C dan D }\end{array}$}} & pengganti semen ataupun pasir. \\
\hline & & Fungsi pasir sendiri sebagai \\
\hline & & pengisi untuk merekatkan semen \\
\hline \multirow{4}{*}{\multicolumn{2}{|c|}{$\begin{array}{l}\text { menunjukkan hasil bahwa } \\
\text { semakin bertambah hari maka } \\
\text { semakin tinggi pula kuat tekan } \\
\text { Paving block. }\end{array}$}} & karena butiran yang lebih kasar \\
\hline & & dibandingakan limbah serbuk \\
\hline & & marmer. Akan tetapi nilai dari \\
\hline & & kuat tekan pada Paving block \\
\hline \multirow{4}{*}{\multicolumn{2}{|c|}{$\begin{array}{l}\text { Hasil yang didapat dari } \\
\text { penelitian ini bahwa limbah } \\
\text { marmer mampu digunakan }\end{array}$}} & yang di buat peneliti masih belum \\
\hline & & memenuhi standart SNI 03-0691- \\
\hline & & 1996 Paving Block Mutu D untuk \\
\hline & & \\
\hline
\end{tabular}

pembuatan Paving block, tidak di 
Pada penelitian lain yang dilakukan Utami (2010) komposisi $0.8 \mathrm{Pc}: 0,2 \mathrm{Lm}: 5 \mathrm{Ps}$ menghasilkan kuat tekan 159,43 $\mathrm{kg} / \mathrm{cm}^{2}$ dan dinyatakan memenuhi syarat untuk paving stone mutu C. Pada variasi campuran 1 : 6 penggantian serbuk marmer 50\% kuat tekan minimum paving block sebesar 15 MPa (Hunggurami 2013).

3. Hasil uji serap air Paving block dengan komposisi campuran Pasir dan Semen sebagai kontrol

Tabel 3. Hasil Uji Serap Air Paving block Kontrol

\begin{tabular}{c|c}
\hline Hari ke- & $\begin{array}{c}\text { Serap air rata-rata Paving Block } \\
(\%)\end{array}$ \\
\hline 7 & 2,12 \\
14 & 2,44 \\
21 & 2,95 \\
28 & 2,53 \\
\hline
\end{tabular}

Menurut SNI 03-0691-1996 standar penyerapan air rata-rata untuk mutu $D$ yang digunakan untuk taman dan pengguna lain yaitu maksimal sebesar $10 \%$. Berdasarkan standart tersebut ke 4 kelompok dengan pengujian hari ke 7, 14, 21, dan 28 telah membuktikan bahwa memenuhi syarat. Berdasarkan standart tersebut ke 4 kelompok dengan pengujian hari ke $7,14,21$, dan 28 telah membuktikan bahwa memenuhi syarat. Pengujian serapan air dilakukan dengan merendam Paving block kedalam air selama 24 jam kemudian di oven pada suhu $110^{\circ}$ selama 24 jam.

Penelitian lain (Nur, 2017) pengujian hari ke-21 dengan perbandingan 1 PC : 6 Ps didapatkan hasil serapan $11,415 \%$.

4. Hasil uji serap air Paving block dengan komposisi campuran Pasir dan Semen dan Limbah Marmer 
Tabel 4. Hasil Uji Serap Air Paving block Komposisi Campuran

\begin{tabular}{|c|c|c|}
\hline \multirow[t]{2}{*}{ Hari ke- } & \multicolumn{2}{|c|}{$\begin{array}{l}\text { Serap air rata-rata Paving Block (\%) } \\
\text { Komposisi Campuran }\end{array}$} \\
\hline & B & C \\
\hline 7 & 5,18 & 3,70 \\
\hline 14 & & 4,28 \\
\hline 21 & & 4,74 \\
\hline 28 & 6,55 & 4,89 \\
\hline \multicolumn{2}{|c|}{ Penelitian ini menunjukkan } & Kuat tekan dan serap air \\
\hline \multicolumn{2}{|c|}{ bahwa menurut SNI 03-0691- } & \\
\hline \multicolumn{2}{|c|}{1996 standar penyerapan air } & limbah marmer dengan 4 variasi \\
\hline \multirow{2}{*}{\multicolumn{2}{|c|}{$\begin{array}{l}\text { rata-rata untuk mutu D yang } \\
\text { digunakan untuk taman dan }\end{array}$}} & perbandingan menunjukkan kua \\
\hline & & \multirow{2}{*}{$\begin{array}{l}\text { tekan belum memenuhi standar } \\
\text { mutu } D \text { taman dan pengguna lair }\end{array}$} \\
\hline \multirow{2}{*}{\multicolumn{2}{|c|}{$\begin{array}{ll}\text { pengguna } & \text { lain yaitu maksimal } \\
\text { sebesar } & 10 \% . \quad \text { Berdasarkan }\end{array}$}} & \\
\hline & & \multirow{2}{*}{$\begin{array}{l}\text { sebesar } 8,5 \mathrm{MPa} \text {, akan tetapi } \\
\text { untuk serap air sudah memenuhi }\end{array}$} \\
\hline \multirow{2}{*}{\multicolumn{2}{|c|}{$\begin{array}{l}\text { standar tersebut ke } 4 \text { kelompok } \\
\text { dengan pengujian hari ke } 7,14 \text {, }\end{array}$}} & \\
\hline & & standart SNI 03-0691-1996 \\
\hline $\begin{array}{l}21 \text {, dan } 28 \text { tel } \\
\text { bahwa mem }\end{array}$ & $\begin{array}{l}\text { tikan } \\
\text { larat. }\end{array}$ & $\begin{array}{l}\text { maksimal penyerapan sebesar } \\
10 \% \text {. }\end{array}$ \\
\hline
\end{tabular}

Semakin lama hari maka daya serap yang diperoleh semakin besar.

Penelitian Hunggurami (2013), dengan menggunakan limbah marmer $50 \%$ serapan air pada perbandingan 1 : 6 yaitu sebesar $9,09 \%$ dengan mutu $D$. Hal ini menunjukkan bahwa semakin banyak jumlah serbuk marmer yang digunakan maka pori-pori semakin sedikit.

\section{Kesimpulan}


Daftar Pustaka

Aditya, C., and A. Halim, 2016. Pemanfaatan Limbah Marmer dan Serbuk Silika pada Industri Bata Beton Pejal dan Berlubang.file:///C:/Users/son y/Downloads/133-73-262-110-20161212\%20(1).pdf. 4 Februari 2018.

Aditya, C., and A. Halim.2017. Pemanfaatan Limbah Marmer Dan Serbuk Zeolit Sebagai Material Pada Bata Ringan CLC (Cellular Lightwight Concrete).file:///C:/Users/son y/Downloads/57-174-1PB.pdf. 5 Februari 2018.

Artiyani, Anis, 2010. Pemanfaatan Abu Pembakaran Sampah Sebagai Bahan Alternatif Pembuatan Paving Block, jurnal Spectra, 84: 3-6.

B, Anggia, dkk, 2016. Analisis Pengaruh Penggantian Sebagian Pasir Dengan Pecahan Batu Bata Terhadap Kuat Tekan Paving Block. Semarang. Politeknik Negeri Semarang.

Dini, 2017.Pemanfaatan Limbah
Marmer Sebagai Bahan
Pembuatan Batako.
Surabaya. Politeknik
Kemenkes Surabaya.

Hunggurami, E., and $M$. Flowrindalauata, 2013.Pemanfaatan Limbah Serbuk Batu Marmer Dari Gunung Batu Naitapan Kabupaten Timor Tengah Selatan Pada Campuran Paving Block,file://C:/Users/sony /Downloads/18943-22663-1SM\%20(1).pdf.2 Februari 2018.

Kristanto, P. 2002. Ekologi Industri. Edisi Kedua.Andi.Yogyakarta.

Rommel, E. 2009.Teknologi Pembuatan Paving Block dengan Material FCA (Fine Coarse Aggregate).Jurnal Gamma Umm, Vol 4 No.2, hal.110-116.

http://researchreport.umm.ac.id/.../163_u mm_rearch_rep.

SNI 03-0691-1996 Bata Beton (Paving block).

Utami, Sri, 2010. Pemanfaatan Limbah Marmer Untuk Pembuatan

Nur, Bryan S, 2017.
Perbandingan Kuat Tekan
Dan Serapan Air Paving
Block Hydraulic Dengan
Variasi Bahan Tambah Fly
Ash. Surakarta. Universitas
Muhammadiyah Surakarta.

